Research Article

\title{
The Approach of Hierarchical Linear Model to Exploring Individual and Team Creativity: A Perspective of Cultural Intelligence and Team Trust
}

\author{
Chenhan Huang, ${ }^{1,2}$ Changqing $\mathrm{He}^{3}$ and Xuesong Zhai ${ }^{4}$ \\ ${ }^{1}$ School of Public Affairs, University of Science and Technology of China, 96 Jinzhai Road, Hefei 230026, Anhui, China \\ ${ }^{2}$ School of Art, Anhui University of Finance and Economics, 962 Caoshan Road, Bengbu 233030, Anhui, China \\ ${ }^{3}$ College of Economics and Management, Nanjing University of Aeronautics and Astronautics, 29 Jiangjun Ave., Nanjing 211106, \\ Jiangsu, China \\ ${ }^{4}$ College of Education, Zhejiang University, 866 Yuhangtang Road, Hangzhou, Zhejiang, China
}

Correspondence should be addressed to Xuesong Zhai; xszhai@zju.edu.cn

Received 19 August 2020; Revised 1 October 2020; Accepted 8 October 2020; Published 24 October 2020

Academic Editor: Shaohui Wang

Copyright (c) 2020 Chenhan Huang et al. This is an open access article distributed under the Creative Commons Attribution License, which permits unrestricted use, distribution, and reproduction in any medium, provided the original work is properly cited.

\begin{abstract}
How to promote the creativity of interorganizational teams has always been the focus among scholars and management practitioners. From the perspective of leadership, this study explores the influence of shared leadership on creativity in interorganizational teams. Specifically, this study integrates leadership perspective with trust perspective and explores the mediating role of team trust between shared leadership and creativity at both team and individual level. In addition, this study examines the moderating effect of the leader's cultural intelligence between shared leadership and team trust based on the perspective of leadership situation. The data comes from 275 employees within 54 interorganizational teams. The results show that shared leadership will promote team trust and team trust plays a key mediating role between shared leadership and creativity. Moreover, the relationship between shared leadership and team trust is moderated by the cultural intelligence of leader, such that the positive relationship will be stronger with high cultural intelligence and weaker with low cultural intelligence.
\end{abstract}

\section{Introduction}

In order to cope with the complex and fierce market competition, more and more organizations tend to seek external cooperation; it is in this context that interorganizational teams emerge as the times require [1-3]. Through the establishment of interorganizational teams, the two partners can complement each other's resources and strengthen the sharing and exchange of information and knowledge, which can effectively promote the generation of creativity [4]. Among the many factors or mechanisms that influence the creativity of the team (or team members), scholars unanimously agree that team trust is one of the most critical factors [5-7]. However, interorganizational teams have many characteristics (see Table 1); for example, members of interorganizational teams come from different organizations and therefore team members have diverse knowledge, skills, behavioral patterns, cultural backgrounds, etc. [8]. This difference will make it more difficult for team members to communicate, exchange knowledge, and establish mutual trust. At the same time, interorganizational teams are built on the link of common tasks and goals. Only when they have mutual trust, sincere cooperation, and interactivity will they be able to accomplish the task and achieve win-win and cooperative creativity. Thus, it can be seen that, on the one hand, interorganizational teams urgently need to build effective trust among members; on the other hand, the establishment of this kind of team trust has become increasingly difficult in the context of interorganizational cooperation. In fact, in the established 
TABLE 1: The features of interorganizational teams and shared leadership.

Characteristics of interorganizational teams

(1) Team members from different organizations have great differences in organizational culture, values, knowledge skills, behavior patterns, etc.

(2) Team members from different organizations rarely have informal communications and therefore lack emotional communication and contact.

(3) Interorganizational teams linked by common tasks and goals often need to cooperate with each other to achieve complementary resources and advantages in order to effectively complete the task.
Characteristics of shared leadership

(1) Sharing of power: team members share leadership, so they will have higher autonomy and decision participation.

(2) Influence mode: different from the traditional vertical leadership that focuses on authority, shared leadership pays more attention to the horizontal mutual effect among team members.

(3) Team members tend to form a common or shared vision. interorganizational teams, a significant part is due to the lack of trust between partners and members of interorganizational teams, ultimately leading to the failure of creativity. In the cooperation between Yidao Yongche and LeTV, for example, it is precisely due to mutual suspicion between the two parties that the relationship has broken down and deteriorated, and ultimately the cooperation has come to an end. The contradictory and cruel reality lies before us: how can we build team trust and promote creativity in interorganizational teams? Solving this problem not only helps to bridge the gaps in existing research on interorganizational teams, but has important guiding significance for effectively promoting the creativity of interorganizational teams.

It is precisely for this purpose that this study attempts to, from the perspective of leadership, explore the important antecedents that influence team trust and then affect the creativity of interorganizational teams. In fact, Burke et al. [9] have suggested in a review study that leadership is one of the most striking determinants of trust; besides, some scholars have argued that leadership is also an important factor influencing team trust [10]. In the general organizational situation, some scholars have empirically studied the influence of different dimensions of transformational leadership style on team trust [5]. In particular, in interorganizational teams, this paper proposes a shared leadership style in which the leadership of a team is shared by multiple members, and they negotiate together, make joint decisions, and jointly take responsibility for the team's tasks [11], which will be an important factor influencing team trust and then creativity. This is also due to the characteristics of shared leadership: shared leadership style lays more emphasis on mutual influence and motivation among team members, and this way of horizontal leadership helps team members understand and trust each other and thus enhances the sense of team trust. However, the existing research has paid little attention to the role of shared leadership in interorganizational teams, especially the integration of the two different perspectives of shared leadership and team trust. In addition, "innovation projects across different organizations often involve independent key persons on a voluntary basis with the absence of a formal structure and no hierarchical controls...." [2]; p. 391); in this situation, team members have a common leadership role or executive leadership behavior, which is especially necessary for creativity [11].
In addition, the success of interorganizational creativity depends not merely on the results of team creativity, but also on the creativity of individual team employees [12, 13]. Different from team creativity, individual creativity mainly refers to the novel and useful ideas related to work flow, product, and services [14]. Although previous literature has pointed out that two creativity types (i.e., team creativity and individual creativity) are related to each other (e.g., [15]), are the influencing mechanisms of the same leadership style (i.e., shared leadership) on both team creativity and individual creativity consistent? It is still largely unknown [16]. Therefore, this study will propose a multilevel model to explore how shared leadership affects team creativity and individual creativity by investigating the key team process of team trust. Furthermore, the existing literature also calls for the need to simultaneously study the impact of cross-level leadership on the results of individual creativity [17]. In view of this, in the context of interorganizational teams, this study will integrate two different perspectives, namely, shared leadership and team trust, to explore whether and how shared leadership can affect team trust and then influence both team and individual creativity.

In addition to exploring the mediating role of team trust between shared leadership and creativity, this paper will further explore the boundary conditions that influence the effects of shared leadership. In the past, only a few studies have explored the contextual factors that affect the role of shared leadership from the perspective of task characteristics, such as task interdependence [18]. So far as the literature is concerned, there is little literature on the boundary conditions of the role of shared leadership from the perspective of individual characteristics of team leaders. In fact, scholars have called for strengthening the exploration of contextual factors of shared leadership. In 2007, for example, Carson et al. suggested that "future work should focus on a more detailed understanding of the nature of shared leadership, its development, and boundary conditions on its effectiveness" (p. 1230). In order to make up for the deficiency of this research, this study considers cultural intelligence of team leaders as a key moderator. The leadership theory has pointed out that the mechanism of leadership is not in a vacuum [19]; thus, the exertion of shared leadership also depends on the specific organizational situation. In interorganizational teams, cultural intelligence-the ability of collecting and processing information in different cultural 
contexts, making the right judgments, and taking corresponding actions-is just such a specific organizational situation [20]. In interorganizational teams, as team members come from organizations with different cultural backgrounds, when team leaders have relatively strong cultural intelligence, it will be conducive to identify the characteristics and expertise of different team members, accelerate power sharing, promote the exertion of effect of shared leadership, and then affect team trust and creativity. Therefore, this study will explore the moderating role of leaders' cultural intelligence. To sum up, the hypothesis model of this study is shown in Figure 1.

Thus, the main contributions of this study are as follows. First of all, in the context of interorganizational teams, it makes clear that shared leadership will be the key to solving the problem of "how to enhance team trust" as an arrangement mechanism of new leadership and team power. This not only enriches the research concerning interorganizational teams, but greatly expands the scope of application of shared leadership, deepening our understanding of shared leadership. It also echoes the appeal of Burke et al. [9] regarding the integration of two different perspectives, namely, leadership and trust. Secondly, in the context of interorganizational teams, it views the impact of trust on two different types of creativity from the perspective of the team, which deepens our influence on trust in different contexts. Besides, based on the perspective of leadership situation and the characteristics of shared leadership, this paper initiatively proposes the important situational role of leaders' cultural intelligence, which deepens our understanding of cultural intelligence and the effectiveness of shared leadership.

\section{Literature Review and Hypotheses Development}

2.1. Team Trust and Creativity. Team trust is a kind of emotional and cognitive team process in which team members have good faith in each other and have strong confidence in the ability of the whole team and trust in other team members in an interorganizational situation $[5,21]$. In recent years, more and more scholars have begun to pay attention to the impact of team trust on creativity. For example, some scholars believe that both goodwill trust and competence trust will produce a positive impact on creativity [22]; Chen et al. [23] also confirmed that, in an R\&D team, trust among team members can effectively promote creativity. Based on previous studies on team trust and creativity, this study specifically points out that team trust is an important source of creativity in the situation of interorganizational teams.

Interorganizational team members' knowledge structures are relatively varied since their prior working experience is different. However, their different knowledge structures may attract other members when team trust is high, which may generate their passion to exchange mind and thinking. In this situation, their trust is conducive to the production of creative thinking and enhance the level of creativity of the whole team.

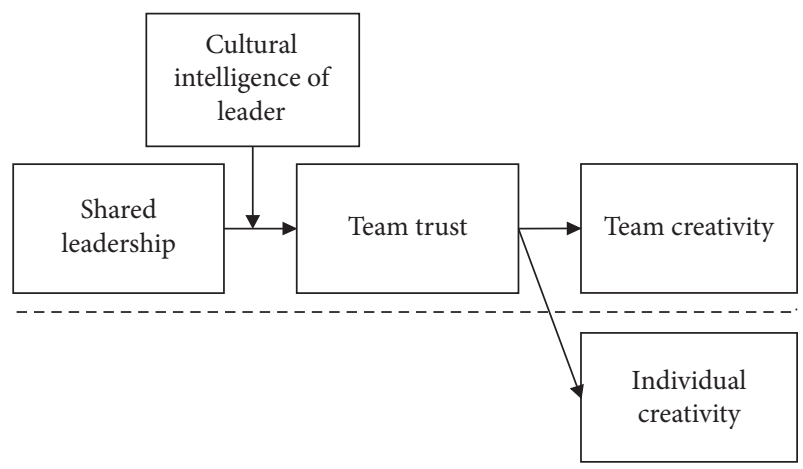

Figure 1: Hypothesis model.

In the next place, emotionally, team trust in interorganizational teams will promote effective communication and exchange as well as the process of knowledge sharing among team members, leading to higher team creativity [4, 5]. The natural features of interorganizational teams cause team members to often have feelings of estrangement with lack of communication and exchange. When team trust is high, it is often able to provide such a mechanism for communication and exchange among team members, which makes team members exchange ideas and viewpoints without reservation, accelerates the process of knowledge sharing, and ultimately improves team creativity [25]. In conclusion, this study presents the following hypotheses.

H1a: in interorganizational teams, team trust will be positively related to team creativity.

In a similar way, in the situation of interorganizational teams, when team trust is at a high level, it will benefit individual employees and promote their individual creativity. When team trust is high, the collision of this opinion and sharing of knowledge will also enable employees to obtain more creative inspirations, leading to the improvement of their individual creativity [6]. Moreover, when interorganizational team members trust each other, individual employees will feel the collective strength. This sense of trust will greatly enhance the psychological security of employees and encourage them to carry out creative activities more boldly.

H1b: in interorganizational teams, team trust will be positively related to individual creativity.

2.2. Shared Leadership and Team Trust. At present, a lot of literature has confirmed that leadership style is an important factor to promote team creativity [26, 27]. For example, Braun et al. [28] pointed out the positive role of transformational leadership style in team trust. Nonetheless, due to the specificity of interorganizational teams, team trust of interorganizational teams seems to be more difficult and complex. Therefore, choosing the type of leadership style or leadership mode is the key to building team trust. Shared leadership puts more emphasis on the sharing of power, and mutual influence among team members [11] makes it easier for team members to build mutual trust and common vision. 
Therefore, this study believes that shared leadership will positively influence team trust, specifically as follows.

First, shared leadership helps to promote the recognition and trust of each other's ability among team members, form a relatively consistent view and cognition, and promote the generation of team trust. Carson et al. [11] emphasize that shared leadership is more of a horizontal leadership style, in which team members interact and make decisions among themselves, rather than a traditional top-down leadership style. Hence, shared leadership can lead to communication and cooperation among team members, and this kind of full communication and sharing is conducive for team members to the appreciation and recognition of each other's ability, ultimately resulting in the generation of team trust.

Moreover, shared leadership can boost emotional communication and exchange among team members, enhance mutual trust, and promote team trust. In other words, shared leadership gives team members greater power and encourages team members to have more opportunities for internal communication and exchange [11]. Frequent and close contact is beneficial to make original team members from different organizations get goodwill from each other and form a close emotional bond. Therefore, shared leadership is beneficial to the generation of team trust. To sum up, this study puts forward the following hypothesis.

$\mathrm{H} 2$ : in interorganizational teams, shared leadership will be positively related to team trust.

2.3. The Mediating Role of Team Trust. At present, some scholars have begun to pay attention to the mediating mechanism of shared leadership on creativity; for instance, $\mathrm{Gu}$ et al. [18] revealed the influence mechanism of shared leadership on team creativity from the perspective of knowledge sharing. Based on the context of interorganizational teams, this study argues that team trust plays a mediating role in the relationship between shared leadership and creativity (at both team and individual level). Shared leadership is conductive to mutual trust among team members, which will provide intrinsic motivation and information communication for creativity at both team and individual level [29]. This is particularly important for interorganizational teams because team members from different cultural backgrounds urgently need to build trust to solve a challenging creative task [30].

From hypothesis 1 and hypothesis 2, we can find that, in interorganizational teams, team trust is the key to influencing creativity, and the establishment of such team trust often needs shared leadership. Specifically, in interorganizational teams, the authorized and horizontal leadership mode of shared leadership can accelerate the frequency of communication, exchange, and sharing among team members and enable team members to form emotionally mutual trust and cognitively mutual trust, while this emotional and cognitive trust will ultimately be the basis for creativity. As a matter of fact, scholars have pointed out that leadership style such as shared leadership can affect teamlevel and individual-level behavioral outcomes, such as creativity [31] by influencing team process (such as team trust). Therefore, this study presents the following hypotheses.

\begin{abstract}
H3a: team trust mediates the relationship between shared leadership and team creativity in interorganizational teams.

$\mathrm{H} 3 \mathrm{~b}$ : team trust mediates the relationship between shared leadership and individual creativity in interorganizational teams.
\end{abstract}

2.4. The Moderating Role of Cultural Intelligence. Previous literature has pointed out that the relationship between shared leadership and creativity is likely to be influenced by some situational factors $[11,32]$. For example, some scholars have discussed the moderating role of task interdependence between shared leadership and creativity [18]. However, most of the existing studies on the boundary conditions of the role of shared leadership focus on task characteristics and organizational structures, and few studies have explored the moderating effect of individual traits of leaders in interorganizational teams. Actually, in interorganizational teams, although power is authorized to each team member, whether the power-sharing mechanism can come into play to a great extent still cannot leave leaders' personal guidance and promotion [11]. Specially, in the situation of interorganizational teams, when leaders themselves have relatively high cultural intelligence, that is, for employees from different organizational and cultural backgrounds, all leaders can interact with them more effectively and adapt to employees in different cultural backgrounds, which will give full play to the role of shared leadership. Hence, this study argues that leader's cultural intelligence will affect the action process of shared leadership in creativity.

This study suggests that cultural intelligence will positively moderate the positive effect of shared leadership on team trust. Firstly, when leader's cultural intelligence is at a high level, the leaders of interorganizational teams can calmly deal with the conflicts and frictions among team members caused by the power-sharing mechanism, accelerating the role of emotional bond brought by shared leadership and enhancing the positive role of shared leadership in team trust [33]. When leaders' cultural intelligence is at a high level, they can not only effectively identify the emotional needs of different team members, but also, when members from different backgrounds have conflicts and frictions, intercede and resolve conflicts and frictions by virtue of their high cultural intelligence, enhance emotional exchange and communication among team members, and realize team trust to the maximum extent. For example, when the members of interorganizational teams from different organizations have disagreements because of their different ideas and goals, the leaders with high cultural intelligence can not only find such differences in a timely manner, but also use their high cultural intelligence for intercession when matters are not serious, enabling team members to live in harmony and enhancing team trust. In the next place, when cultural intelligence is stronger, leaders can be more effective in identifying the ability of team 
employees from different organizations. This will accelerate the cognitive consistency of shared leadership, speed up the understanding and collaboration among team members, and increase the positive role of shared leadership in team trust [34]. The leaders with high cultural intelligence, for instance, can effectively identify the strengths and weaknesses of different employees, which can tilt the team's resources to those who need them more; besides, the power-sharing mechanism can be carried out more smoothly, which can accelerate mutual appreciation and recognition among team members, enhance the role of shared leadership, and promote team trust. Therefore, this study proposes the following hypothesis.

H4: leader's cultural intelligence will moderate the relationship between shared leadership and team trust, such that this positive relationship is stronger when leader's cultural intelligence is higher.

\section{Method}

3.1. Sample and Procedures. The research team cooperates with a university in China to issue survey questionnaires. With its assistance, the research team distributes a total of 68 questionnaires of interorganizational teams. These 68 teams come from 19 different companies, and their industries include information technology, manufacturing industry, medical treatment, and scientific research institutions. When conducting the study, the research team takes a variety of approaches to ensure that respondents are clear about the purpose of the study: first of all, there will be a special researcher in this research team to contact the selected interorganizational teams and explain the purpose of this study; secondly, the cover of the paper questionnaire will have a special page to introduce the purpose of this study and fill in the points for attention; in addition, every variable measurement item in the questionnaire is preceded by an introduction to remind the respondents that the investigation objects are the interorganizational cooperation teams. "Among team members of interorganizational cooperative creativity team...," for example, the purpose of doing so is to repeatedly remind the respondents that the investigation objects are the interorganizational cooperation teams rather than the original department teams of their own work units.

In order to increase the recovery rate of questionnaires, we adopt two ways. In the first place, before the research, the research team will communicate and exchange information with the tested interorganizational teams, try to make explanation and illustration to make the investigated interorganizational teams fully understand the purpose of this study, and invite them to participate in this study. Next, after the questionnaires are issued, the research team also follows up the filling of questionnaires by means of subsequent telephone contacts or e-mail contacts. Finally, the research team recovers effective questionnaires from 54 teams, including 54 team leaders and 275 employees, with a recovery rate of $79.4 \%$. Among these 54 sample teams, those whose team size is less than or equal to 5 persons take up $7.4 \%$, those whose team size is from 6 persons to 10 persons account for $40.7 \% ; 27.8 \%$ of the teams have 11 persons to 15 persons; and $24.1 \%$ of the teams have 16 persons and above. Those with the establishment period of 1 to 6 months take up $16.6 \%$; those with the establishment period of 7 to 12 months account for $24.1 \% ; 24.1 \%$ of the teams have the establishment period of 13 to 36 months; and those with the establishment period of 36 months and above account for $35.2 \%$.

3.2. Measurement. In order to ensure the validity and reliability of measurement tools, this study tries to adopt a mature scale of the existing literature and then make appropriate revision according to the purpose and specific situation of the research. Prior to the formal finalization and investigation of the questionnaires, one of the authors makes presurvey questionnaires to evaluate the appropriateness of the design and wording of questionnaires and then revises the questionnaires according to the advice provided by the presurvey respondents. Each variable is measured with 5point Likert scale.

(1) Shared leadership. There are 10 items in the scale of shared leadership, which come from Shane Wood and Fields [35]. These items are mainly used to measure the degree to which team members participate in the decision-making process of teams. The scale is filled by team members, for example, "team members in interorganizational teams share in deciding on the best course of action when a problem faces the team." In order to ensure the reliability and validity of the scale, this study finally retains seven items with the highest loading value.

(2) Team trust. It is derived from the trust scale prepared by Dakhli and De Clercq [36]. The scale is filled in by team members and includes 3 items, for example, "team members in interorganizational teams have mutual trust and are supportive of change."

(3) Cultural intelligence. With reference to the cultural intelligence scale developed by Ang et al. [37], the scale measures the cultural intelligence of interorganizational team leaders from different aspects such as metacognition, cognition, motivation, and behavior. The scale is completed by the leaders of interorganizational teams with 20 items, for example, "I enjoy interacting with people from different cultures."

(4) Individual creativity. The variable of individual creativity adopts the scale developed by Dul et al. [38] with three items. These items are used to measure the extent to which individuals come up with new ideas. For example, "in my work, I often have new and creative ideas" ( $1=$ strongly disagree; $5=$ strongly agree).

(5) Team creativity. The variable scale is selected from Shin and Zhou [14] with four items. These items are used to measure the extent to which new ideas are generated by interorganizational teams. This scale is filled out by leaders in the interorganizational teams, 
for instance, "how well does your team produce new ideas?" ( 1 = strongly poorly; $5=$ very much).

In addition, with reference to previous studies by scholars, we controlled for gender, age, and educational level at the individual level [39], and team's tenure and size at the team level [40].

3.3. Data Aggregation. To determine if individual-level data can be aggregated to the team level, this study examines intragroup consistency and intergroup variance [41]. Intragroup consistency is tested by Rwg index while intergroup variance is tested by ICC(1) and ICC(2). Previous literature has pointed out that shared leadership is a teamlevel variable [42]. Data analysis indicates that $\operatorname{ICC}(1)=0.17$, $\operatorname{ICC}(2)=0.52$, so shared leadership can be aggregated into a team-level variable. Furthermore, previous literature has revealed that team trust is also a variable at the team level (e.g., [5]). The result shows that ICC(1) and ICC(2) of team trust are 0.21 and 0.57 , respectively. The ICC result demonstrates that shared leadership and team trust can indeed be aggregated into a team-level variable (e.g., [16]). In addition, in order to further determine that shared leadership and team trust can be aggregated into team-level variables from employees' individual level, this study examines internal consistency within the group. The result suggests that the average Rwg scores of shared leadership and team trust are both 0.92 , and all scores exceed the threshold of 0.70 [41]. The above result manifests that the data of shared leadership and team trust can be aggregated into team-level variables.

\section{Data Analysis and Results}

4.1. Analysis of Reliability and Validity. Before hypotheses testing, we have first performed a confirmatory factor analysis (CFA) on the main variables. The loading values, coefficient of internal consistency (Cronbach's alpha), composite reliability, and AVE values of the main study variables are shown in Table 2. Table 2 shows that the reliability (Cronbach's alpha) and composite reliability of various variables are between 0.733 and 0.903 , which are higher than the threshold of 0.70 . The scores of average variance extraction value (AVE) of all variables are between 0.505 and 0.766 , which exceed the threshold of 0.50 .

To further verify the discriminant validity of various variables, this study adopts the comparison method of average variation extraction (AVE), and the result shows that the AVE value of each variable is higher than the critical value of 0.5 . Furthermore, as shown in Table 3, the AVE square root of each variable is greater than the correlation coefficient between the variables, which further explains that there is good discriminant validity between the variables.

4.2. Descriptive Statistics of Variables. Table 3 summarizes the mean value, standard deviation, and correlation coefficient of all variables. We found that shared leadership and team trust are both significantly correlated to team creativity.
TABLE 2: Composite reliability and average variance extracted (AVE).

\begin{tabular}{lccccc}
\hline Variables & Items & $\begin{array}{c}\text { Factors } \\
\text { loading }\end{array}$ & $\begin{array}{c}\text { Cronbach's } \\
\text { alpha }\end{array}$ & $\begin{array}{c}\text { Composite } \\
\text { reliability }\end{array}$ & AVE \\
\hline $\begin{array}{l}\text { Shared } \\
\text { leadership }\end{array}$ & 7 & $0.585 \sim 0.726$ & 0.798 & 0.803 & 0.505 \\
$\begin{array}{l}\text { Team trust } \\
\begin{array}{l}\text { Cultural } \\
\text { intelligence }\end{array}\end{array}$ & 20 & $0.795 \sim 0.815$ & 0.733 & 0.849 & 0.652 \\
$\begin{array}{l}\text { Individual } \\
\text { creativity }\end{array}$ & 3 & $0.766 \sim 0.773$ & 0.769 & 0.887 & 0.662 \\
$\begin{array}{l}\text { Team } \\
\text { creativity }\end{array}$ & 4 & $0.724 \sim 0.788$ & 0.759 & 0.885 & 0.659 \\
\hline
\end{tabular}

Note. ML: moral leadership, LMX: leader-member exchange, TI: team identification, EC: employee creativity. ${ }^{*} p<0.05 ;{ }^{* *} p<0.01$; ${ }^{* * *} p<0.00$. $N=275$.

\subsection{Hypothesis Test}

4.3.1. Team-Level Analysis Result. To test the team-level hypotheses, we use hierarchical regression analyses.

$\mathrm{H} 1 \mathrm{a}$ assumes that team trust will positively affect team creativity. As shown in Model 5 of Table 4 , team trust positively affects team creativity $(\beta=0.374, p<0.01 p<0.01)$, thereby supporting H1a.

At the same time, model 1 in Table 4 suggests that shared leadership positively affects team trust $(\beta=0.642, p<0.001)$. Hence, we support hypothesis 2 .

The result of Table 4 also shows that the coefficient for shared leadership on team creativity decreases when the effect of team trust is included in the regression equation. The coefficient decreases from $0.407(p<0.01$, model 8$)$ to 0.279 ( $p<0.05$, model 9). Thus, H3a is supported.

$\mathrm{H} 4$ assumes that leader's cultural intelligence can moderate the relationship between shared leadership and team trust, where such positive relationship will become stronger under higher cultural intelligence. The result of model 3 in Table 4 suggests that interaction between shared leadership and cultural intelligence significantly relates to team trust $(\beta=0.222, p<0.05)$, supporting $\mathrm{H} 4$.

We further calculate the simple slopes for the relationship between shared leadership and team trust at higher $($ mean + s.d.) and lower (mean - s.d.) level of cultural intelligence [43]. Figure 2 shows that cultural intelligence amplifies the positive relationship between shared leadership and team trust. As expected, the relationship between shared leadership and team trust is significant (simple slope $=0.432$, $p<0.05)$ at low levels of cultural intelligence and becomes stronger (simple slope $=0.876, p<0.01$ ) at high levels of cultural intelligence.

4.3.2. Hierarchical Analysis Result. In this study, the Hierarchical Linear Model (HLM) is used to examine the hierarchical research hypothesis.

Table 5 summarizes the analysis results of HLM. In step 1 , model 1 shows that shared leadership is positively related to individual creativity $(\beta=0.757, p<0.001)$. In step 2 , team trust should be positively related to individual creativity 
TABLE 3: Means, standard deviations, and correlation.

\begin{tabular}{|c|c|c|c|c|c|c|c|c|}
\hline Variables & Mean & s.d. & 1 & 2 & 3 & 4 & 5 & 6 \\
\hline \multicolumn{9}{|l|}{ Individual-level variables } \\
\hline (1) Gender & 0.72 & 0.47 & & & & & & \\
\hline (2) Age & 2.47 & 0.62 & 0.07 & & & & & \\
\hline (3) Education level & 3.12 & 0.67 & 0.04 & -0.04 & & & & \\
\hline (4) Individual creativity & 3.97 & 0.55 & -0.03 & $0.131^{*}$ & -0.08 & $(0.875)$ & & \\
\hline \multicolumn{9}{|l|}{ Team-level variables } \\
\hline (1) Team size & 6.76 & 1.59 & & & & & & \\
\hline (2) Team tenure & 3.72 & 1.10 & $-0.23+$ & & & & & \\
\hline (3) Shared leadership & 3.88 & 0.34 & 0.13 & 0.21 & $(0.711)$ & & & \\
\hline (4) Team trust & 4.16 & 0.30 & -0.11 & 0.21 & $0.63^{* * *}$ & $(0.807)$ & & \\
\hline (5) Cultural intelligence & 3.97 & 0.35 & 0.16 & 0.16 & 0.34 & 0.19 & $(0.814)$ & \\
\hline (6) Team creativity & 3.94 & 0.31 & -0.10 & $0.29^{*}$ & $0.43^{* * *}$ & $0.42^{* *}$ & $0.60^{* * *}$ & $(0.812)$ \\
\hline
\end{tabular}

Note. $N$ (employees) $=275 ; N$ (leaders/teams) $=54$. Square roots of AVE are in parentheses on the diagonal. ${ }^{*} p<0.05 ;{ }^{* *} p<0.01 ;{ }^{* * *} p<0.001$.

TABLE 4: Regression results for team-level analysis.

\begin{tabular}{|c|c|c|c|c|c|c|c|c|}
\hline \multirow{2}{*}{ Level and variables } & \multicolumn{3}{|c|}{ Trust } & \multicolumn{5}{|c|}{ Team creativity } \\
\hline & Model 1 & Model 2 & Model 3 & Model 4 & Model 5 & Model 6 & Model 7 & Model 8 \\
\hline \multicolumn{9}{|l|}{ Level 2} \\
\hline Team size & -0.185 & -0.185 & -0.125 & -0.035 & -0.010 & -0.134 & -0.086 & 0.005 \\
\hline Team tenure & 0.029 & 0.026 & 0.052 & $0.281^{*}$ & 0.210 & 0.111 & 0.027 & 0.012 \\
\hline SL & $0.642^{* * *}$ & $0.632^{* * *}$ & $0.654^{* * *}$ & & & & $0.407^{* *}$ & $0.279^{*}$ \\
\hline Trust & & & & & $0.374^{* *}$ & $0.276^{*}$ & & $0.200^{*}$ \\
\hline CI & & 0.029 & -0.006 & & & $0.550^{* * *}$ & & \\
\hline \multicolumn{9}{|l|}{ Interaction item } \\
\hline $\mathrm{SL} \times \mathrm{CI}$ & & & $0.222^{*}$ & & & & & \\
\hline$R^{2}$ & 0.428 & 0.429 & 0.474 & 0.085 & 0.218 & 0.491 & 0.530 & 0.667 \\
\hline$\Delta R^{2}$ & 0.428 & 0.001 & 0.044 & 0.085 & 0.133 & 0.272 & 0.530 & 0.137 \\
\hline$F$ & $12.496^{* * *}$ & $9.211^{* * *}$ & $8.641^{* * *}$ & 2.372 & $4.654^{* *}$ & $11.802^{* * *}$ & $18.822^{* * *}$ & $24.588^{* * *}$ \\
\hline$\Delta F$ & $12.496^{* * *}$ & 0.062 & $4.058^{*}$ & 2.372 & $8.519^{* *}$ & $26.207^{* * *}$ & $18.822^{* * *}$ & $20.202^{* * *}$ \\
\hline
\end{tabular}

Note. $N=54$. SL: shared leadership; CI: cultural intelligence of leader.

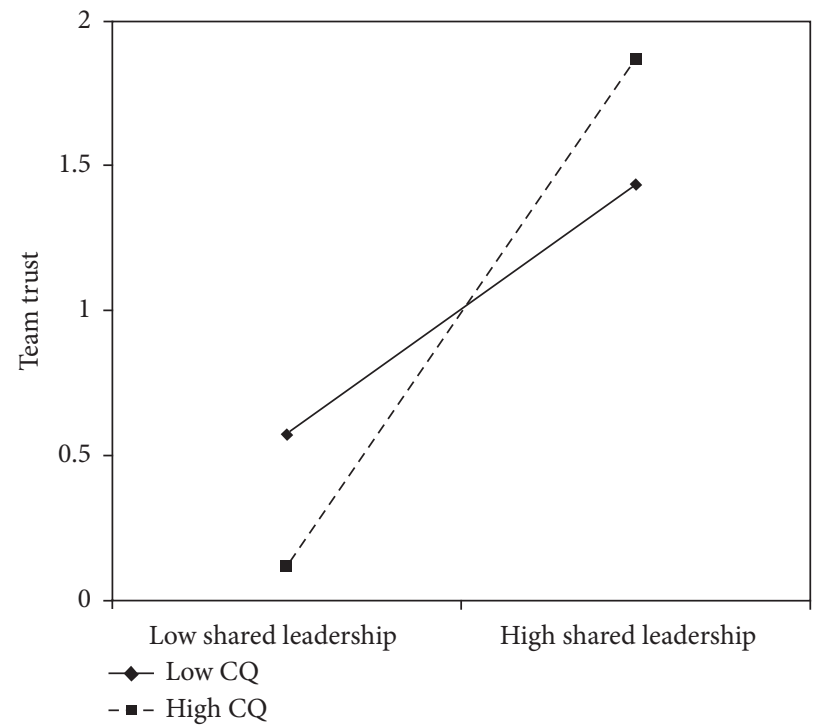

FIGURE 2: Moderating effect of leader's cultural intelligence on the relationship between shared leadership and team trust.

(H1b). The result of model 3 demonstrates that team trust is positively related to individual creativity $(\beta=0.667$, $p<0.001$ ), thereby supporting hypothesis 1 b. In step 3 , the coefficient for shared leadership on individual creativity decreases when the effect of team trust is included in the regression equation. The coefficient decreases from 0.757 
TABLE 5: HLM results for cross-level analysis.

\begin{tabular}{lccc}
\hline \multirow{2}{*}{ Level and variables } & \multicolumn{3}{c}{ Individual creativity } \\
& Model 1 & Model 2 & Model 3 \\
\hline Level 1 & & & \\
$\quad$ Gender & 0.006 & 0.007 & 0.004 \\
Age & 0.111 & 0.113 & 0.106 \\
$\quad$ Education level & 0.022 & 0.022 & 0.017 \\
Level 2 & & & \\
$\quad$ Team size & -0.025 & -0.015 & 0.009 \\
Team tenure & 0.030 & 0.029 & 0.053 \\
$\quad$ Shared leadership & $0.757^{* * *}$ & $0.602^{* * *}$ & \\
$\quad$ Team trust & & $0.257^{*}$ & $0.667^{* * *}$ \\
\hline
\end{tabular}

Note. $N$ (subordinates) $=275 ; N$ (leaders/teams) $=54 .{ }^{*} p<0.05 ;{ }^{* *} p<0.01$; ${ }^{* * *} p<0.001$

$(p<0.001$, model 1$)$ to $0.602(p<0.001$, model 2$)$, supporting hypothesis $3 \mathrm{~b}$.

\section{Conclusion and Discussion}

Interorganizational teams proved to be a very effective way of cooperative creativity. Therefore, how to explore the generation mechanism of creativity in the context of interorganizational teams seems to be especially necessary. In particular, based on the characteristics of interorganizational teams, this study proposes that team trust will be the key for promoting interorganizational creativity; then, from the perspective of leadership, it suggests that shared leadership as an emerging power-sharing system and arrangement will be the key factor for building team trust. On this basis, this study also investigates the situational moderating role of leaders' cultural intelligence in the relationship between shared leadership and team trust.

5.1. Theoretical Implications. The greatest contribution of this study lies in its confirmation of how and when shared leadership affects creativity at both team and individual level. Hence, important theoretical implications to the literature of shared leadership and creativity are offered in this study.

First, we propose and empirically test a theoretical model that provides a nuanced depiction of how and under what conditions shared leadership influences creativity. Our study also enriches the literature regarding the consequences of shared leadership by verifying a positive association linking shared leadership to creativity at both team and individual level. In this process, we contribute to shared leadership literature by demonstrating that shared leadership, either at the individual or team level, is valuable. To our knowledge, no prior research has considered team trust as a critical mediating mechanism linking shared leadership and creativity. Previous research has also shown that some potential team processes (such as knowledge sharing) can mediate the relationship between shared leadership and creativity [18]. Other scholars also try to interpret the relationship between leadership and creativity from the perspective of trust [6]. Therefore, the results of this study are also further expansion of the literature in this aspect. We go further in this theoretical model by highlighting the moderating role of cultural intelligence in strengthening the above link. Indeed, shared leadership, cultural intelligence, and team trust constitute three important areas in organizational behavior research that have not been integrated until now as a means of predicting creativity at both team and individual level.

Second, our findings contribute to the creativity literature by identifying the mediating role of team trust. This study has confirmed that team trust is a key mediating mechanism between shared leadership and creativity, which expands our understanding of the creativity of interorganizational teams. Although the existing research has proven that, in general team situations, team trust is the key to unlocking team creativity (e.g., [5]), and some scholars have also pointed out that team trust may play a key role in interorganizational alliances (such as knowledge sharing, information exchange, and team learning), there is still a great shortage of empirical research in interorganizational team context. In this context, this study empirically tests the key impact of team trust on the creativity in interorganizational teams, which helps us have a better understanding of the source of creativity in interorganizational teams.

Third, we probe into the situational variables that affect the process of shared leadership [44]. We draw the conclusion that leader's cultural intelligence can strengthen the positive relationship between shared leadership and team trust. The result indicates that team trust and creativity are based not only on shared leadership, but also on leader's cultural intelligence. This finding responds to the previous scholars' call for exploring the situational factors that play a role in shared leadership [11].

5.2. Practical Implications. The results of this paper are of great enlightenment significance in respect of how to carry out better creativity in interorganizational teams.

First, interorganizational teams should establish mutual trust among each other. The research shows that team trust is a key factor in creativity. Hence, the key to the success of creativity is to build trust between the two partners and among team members. In the process of interorganizational team creativity, only by offering mutual help to make up for what the other lacks rather than "holding back a trick or two," is it possible to establish mutual trust among members to the maximum extent, boost the sharing of knowledge and information, and accelerate the production of creativity.

What is more, the shared leadership model should be adopted and applied widely. The research result proves that shared leadership has a positive impact on both team trust and cooperative creativity. Therefore, in the context of interorganizational teams, it is necessary to use this new power-sharing mechanism to mobilize the enthusiasm of every member in the teams to the maximum extent, give play to their creativity, and promote the formation of cooperative creativity.

Finally, when considering the interorganizational team leadership, we must pay special attention to examining its cultural intelligence. Although research has shown that the use of shared leadership is an effective 
power distribution model and institutional arrangement, the research conclusion reveals that leaders' personal ability traits, especially cultural intelligence, still play a vital role in it. Hence, when selecting and appointing interorganizational team leaders, what calls for special attention is to examine the cultural intelligence of leaders and preferably choose those with high cultural intelligence, which helps to accelerate the exertion of the role of shared leadership and achieve the success of interorganizational teamwork.

\subsection{Limitations. This study has some limitations as well.}

In the first place, this study takes a self-evaluation approach to measure employees' individual creativity. Although most of the current literature uses the method of leadership assessment to evaluate employees' individual creativity [16], the method of employees' self-evaluation can be accepted as well [38, 45]. Specifically, in the context of this study, the method of employees' individual creativity may be more applicable to the measurement of individual creativity. Firstly, in the context of interorganizational teams, it is very difficult for a team leader to have an accurate and comprehensive observation of each member's creativity. Besides, creativity itself is a subtle behavior, and only the innovators themselves are more aware of how much creative ideas they have play a role in their work assignments [38, 45]; spectators may not necessarily fully and accurately understand the creative ability of a certain employee, so they may not be able to accurately evaluate the performance of an employee's individual creativity [46]. In the next place, although the self-assessment method can bring subjective errors, previous literature has pointed out that individual creativity evaluated by oneself and individual creativity evaluated by others are highly relevant [47]; moreover, subsequent empirical studies also suggest that individual creativity evaluated by oneself also has a good validity [38]. Nonetheless, future research may adopt a more objective approach or a combination of subjective and objective approach with multiple evaluation subjects to measure employees' individual creativity so as to avoid possible problems.

Furthermore, it belongs to cross-sectional research in terms of research design. Since cross-section data cannot provide strong evidence for the causal relationship between variables, future research can employ the method of longitudinal research to test the influence of mediating and causal relationship between mediating variables.

Finally, when examining situational factors, we only consider cultural intelligence-individual traits of leaders. However, in future studies, other situational factors, such as the personal qualities of employees, also need to be taken into consideration.

\section{Data Availability}

All data, models, or code generated or used during the study are proprietary or confidential in nature and may only be provided with restrictions.

\section{Conflicts of Interest}

The authors declare that there are no conflicts of interest regarding the publication of this paper.

\section{Authors' Contributions}

Chenhan Huang and Changqing He contributed equally to this work.

\section{Acknowledgments}

This research work was supported by the 2020 Humanities and Social Science Projects of the Ministry of Education (Grant no. 20YJC880118).

\section{References}

[1] D. Faems, B. Van Looy, and K. Debackere, "Interorganizational collaboration and innovation: toward a portfolio approach," Journal of Product Innovation Management, vol. 22, no. 3, pp. 238-250, 2005.

[2] A. Rese, H.-G. Gemünden, and D. Baier, "Too many cooks spoil the broth': key persons and their roles in inter-organizational innovations," Creativity and Innovation Management, vol. 22, no. 4, pp. 390-407, 2013.

[3] R. M. Stock and N. A. Zacharias, "Patterns and performance outcomes of innovation orientation," Journal of the Academy of Marketing Science, vol. 39, no. 6, pp. 870-888, 2011.

[4] N. Panteli and S. Sockalingam, "Trust and conflict within virtual inter-organizational alliances: a framework for facilitating knowledge sharing," Decision Support Systems, vol. 39, no. 4, pp. 599-617, 2005.

[5] K. Boies, J. Fiset, and H. Gill, "Communication and trust are key: unlocking the relationship between leadership and team performance and creativity," The Leadership Quarterly, vol. 26, no. 6, pp. 1080-1094, 2015.

[6] N. Y. Jo, K. C. Lee, D. S. Lee, and M. Hahn, "Empirical analysis of roles of perceived leadership styles and trust on team members' creativity: evidence from Korean ICT companies," Computers in Human Behavior, vol. 42, pp. 149-156, 2015.

[7] J. Wu, H. Zhao, and D. Pan, "Effects of different trust on team creativity: taking knowledge sharing as a mediator," in Proceedings of the International Symposium on Knowledge and Systems Sciences, Springer Singapore, Kobe, Japan, pp. 44-56, November 2016.

[8] H. C. Dekker, "Control of inter-organizational relationships: evidence on appropriation concerns and coordination requirements," Accounting, Organizations and Society, vol. 29, no. 1, pp. 27-49, 2004.

[9] C. S. Burke, D. E. Sims, E. H. Lazzara, and E. Salas, "Trust in leadership: a multi-level review and integration," The Leadership Quarterly, vol. 18, no. 6, pp. 606-632, 2007.

[10] P. Lee, N. Gillespie, L. Mann, and A. Wearing, "Leadership and trust: their effect on knowledge sharing and team performance," Management Learning, vol. 41, no. 4, pp. 473-491, 2010.

[11] J. B. Carson, P. E. Tesluk, and J. A. Marrone, "Shared leadership in teams: an investigation of antecedent conditions and performance," Academy of Management Journal, vol. 50, no. 5, pp. 1217-1234, 2007.

[12] M. Hoegl and K. P. Parboteeah, "Creativity in innovative projects: how teamwork matters," Journal of Engineering and Technology Management, vol. 24, no. 1-2, pp. 148-166, 2007.

[13] H. Liao, D. Liu, and R. Loi, "Looking at both sides of the social exchange coin: a social cognitive perspective on the joint effects of relationship quality and differentiation on creativity," Academy of Management Journal, vol. 53, no. 5, pp. 1090-1109, 2010. 
[14] S. J. Loi and J. Zhou, "When is educational specialization heterogeneity related to creativity in research and development teams? Transformational leadership as a moderator," Journal of Applied Psychology, vol. 92, no. 6, pp. 1709-1721, 2007.

[15] A. Pirola-Merlo and L. Mann, "The relationship between individual creativity and team creativity: aggregating across people and time," Journal of Organizational Behavior, vol. 25, no. 2, pp. 235-257, 2004.

[16] Y. Gong, T.-Y. Kim, D.-R. Lee, and J. Zhu, "A multilevel model of team goal orientation, information exchange, and creativity," Academy of Management Journal, vol. 56, no. 3, pp. 827-851, 2013.

[17] D. T. Yoshida, S. Sendjaya, G. Hirst, and B. Cooper, "Does servant leadership foster creativity and innovation? A multilevel mediation study of identification and prototypicality," Journal of Business Research, vol. 67, no. 7, pp. 1395-1404, 2014.

[18] J. Gu, Z. Chen, Q. Huang, H. Liu, and S. Huang, "A multilevel analysis of the relationship between shared leadership and creativity in inter-organizational teams," The Journal of Creative Behavior, vol. 52, no. 2, pp. 109-126, 2018.

[19] D. V. Day, P. Gronn, and E. Salas, "Leadership in team-based organizations: on the threshold of a new era," The Leadership Quarterly, vol. 17, no. 3, pp. 211-216, 2006.

[20] P. C. Earley and E. Mosakowski, "Cultural intelligence," Harvard Business Review, vol. 82, no. 10, pp. 139-158, 2004.

[21] C. W. Langfred, "Too much of a good thing? Negative effects of high trust and individual autonomy in self-managing teams," Academy of Management Journal, vol. 47, no. 3, pp. 385-399, 2004.

[22] A. Brattström, H. Löfsten, and A. Richtnér, "Creativity, trust and systematic processes in product development," Research Policy, vol. 41, no. 4, pp. 743-755, 2012.

[23] M. H. Chen, Y. C. Chang, and S. C. Hung, "Social capital and creativity in R\&D project teams," $R$ \& D Management, vol. 38, no. 1, pp. 21-34, 2008.

[24] S. B. Sitkin, D. M. Rousseau, R. S. Burt, and C. Camerer, "Special topic forum on trust in and between organizations," Academy of Management Review, vol. 23, no. 3, pp. 387-531, 1998.

[25] F. Bidault and A. Castello, "Trust and creativity: understanding the role of trust in creativity-oriented joint developments," R๘D Management, vol. 39, no. 3, pp. 259-270, 2009.

[26] K. T. Dirks and D. L. Ferrin, "Trust in leadership: meta-analytic findings and implications for research and practice," Journal of Applied Psychology, vol. 87, no. 4, pp. 611-628, 2002.

[27] M.-J. Shen and M.-C. Chen, "The relationship of leadership, team trust and team performance: a comparison of the service and manufacturing industries," Social Behavior and Personality: An International Journal, vol. 35, no. 5, pp. 643-658, 2007.

[28] S. Braun, C. Peus, S. Weisweiler, and D. Frey, "Transformational leadership, job satisfaction, and team performance: a multilevel mediation model of trust," The Leadership Quarterly, vol. 24, no. 1, pp. 270-283, 2013.

[29] Z. Song, Q. Gu, and F. L. Cooke, "The effects of high-involvement work systems and shared leadership on team creativity: a multilevel investigation," Human Resource Management, vol. 59, no. 3, pp. 201-213, 2020.

[30] A. Serban and A. J. B. Roberts, "Exploring antecedents and outcomes of shared leadership in a creative context: a mixedmethods approach," The Leadership Quarterly, vol. 27, no. 2, pp. 181-199, 2016.
[31] V. C. Nicolaides, K. A. LaPort, T. R. Chen et al., "The shared leadership of teams: a meta-analysis of proximal, distal, and moderating relationships," The Leadership Quarterly, vol. 25, no. 5, pp. 923-942, 2014.

[32] D. S. DeRue, "Adaptive leadership theory: leading and following as a complex adaptive process," Research in Organizational Behavior, vol. 31, pp. 125-150, 2011.

[33] D. C. Thomas, "Domain and development of cultural intelligence," Group \& Organization Management, vol. 31, no. 1, pp. 78-99, 2006.

[34] H. C. Triandis, "Cultural intelligence in organizations," Group \& Organization Management, vol. 31, no. 1, pp. 20-26, 2006.

[35] M. Shane Wood and D. Fields, "Exploring the impact of shared leadership on management team member job outcomes," Baltic Journal of Management, vol. 2, no. 3, pp. 251-272, 2007.

[36] M. Dakhli and D. De Clercq, "Human capital, social capital, and innovation: a multi-country study," Entrepreneurship \& Regional Development, vol. 16, no. 2, pp. 107-128, 2004.

[37] S. Ang, L. Van Dyne, C. Koh et al., "Cultural intelligence: its measurement and effects on cultural judgment and decision making, cultural adaptation and task performance," Management and Organization Review, vol. 3, no. 3, pp. 335-371, 2007.

[38] J. Dul, C. Ceylan, and F. Jaspers, "Knowledge workers' creativity and the role of the physical work environment," Human Resource Management, vol. 50, no. 6, pp. 715-734, 2011.

[39] T. M. Amabile, "A model of creativity and innovation in organizations," Research in Organizational Behavior, vol. 10, no. 1, pp. 123-167, 1988.

[40] D. A. Harrison and K. J. Klein, "What's the difference? diversity constructs as separation, variety, or disparity in organizations," Academy of Management Review, vol. 32, no. 4, pp. 1199-1228, 2007.

[41] L. R. James, R. G. Demaree, and G. Wolf, "Estimating withingroup interrater reliability with and without response bias," Journal of Applied Psychology, vol. 69, no. 1, pp. 85-98, 1984.

[42] C. L. Pearce and H. P. Sims Jr., "Shared leadership: toward a multi-level theory of leadership," in Advances in Inter Disciplinary Studies of Work Teams: Team Leadership, M. Beyerlein, D. Johnson, and S. Beyerlein, Eds., pp. 115-139, JAI Press, Greenwich, CT, USA, 2000.

[43] L. S. Aiken and S. G. West, Multiple Regression: Testing and Interpreting Interactions, Sage Publications, NewburyPark, CA, USA, 1991.

[44] M. D. Ensley, K. M. Hmieleski, and C. L. Pearce, "The importance of vertical and shared leadership within new venture top management teams: implications for the performance of startups," The Leadership Quarterly, vol. 17, no. 3, pp. 217-231, 2006.

[45] C. E. Shalley, L. L. Gilson, and T. C. Blum, "Interactive effects of growth need strength, work context, and job complexity on self-reported creative performance," Academy of Management Journal, vol. 52, no. 3, pp. 489-505, 2009.

[46] J. Zhou, S. J. Shin, and A. A. Cannella, "Employee self-perceived creativity after mergers and acquisitions: interactive effects of threat-opportunity perception, access to resources, and support for creativity," Journal of Applied Behavioral Sciences, vol. 44, no. 4, pp. 397-421, 2008.

[47] C. M. Axtell, D. J. Holman, K. L. Unsworth, T. D. Wall, P. E. Waterson, and E. Harrington, "Shopfloor innovation: facilitating the suggestion and implementation of ideas," Journal of Occupational and Organizational Psychology, vol. 73, no. 3, pp. 265-285, 2000. 